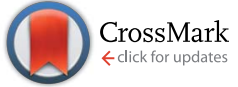

Cite this: J. Mater. Chem. A, 2015, 3, 21227

Received 11th August 2015

Accepted 9th September 2015

DOI: $10.1039 / c 5 t a 06304 c$

www.rsc.org/MaterialsA

\section{Synthesis of efficient photocatalysts for water oxidation and dye degradation reactions using $\mathrm{CoCl}_{2}$ eutectics $\uparrow$}

\author{
Christian Fettkenhauer, ${ }^{a}$ Xinchen Wang, ${ }^{b}$ Kamalakannan Kailasam, $t^{\mathrm{C}}$ \\ Markus Antonietti ${ }^{a}$ and Dariya Dontsova*a
}

A simple one-step procedure for the preparation of cobalt oxide-carbon nitride composites by carrying out the thermal condensation reaction of carbon nitride precursors in cobalt(॥) chloride-containing salt melts is developed. This method enables us to control the structure of the polymer constituent by the proper selection of the second eutectic component. In this respect, alkali metal chlorides and zinc chloride give rise to poly(triazine imides), while tin(॥) chloride delivers melon-based polymers. The crystallinity of the carbon nitride polymer phase can be influenced by varying the concentration of the precursor in the melt. On the other hand, cobalt oxide loading in the final products can be increased by decreasing the precursor concentration in the melt. The products are highly active photocatalysts for Rhodamine $\mathrm{B}$ degradation as exemplified by $\mathrm{SnCl}_{2} / \mathrm{CoCl}_{2}$-derived solids, and the water oxidation reaction (WOR). The activity of the products in the WOR is comparable with that of the bench composite photocatalyst prepared by using the three-step procedure that includes the synthesis of $\mathrm{Co}_{3} \mathrm{O}_{4}$ nanoparticles as a separate step, thus illustrating the advantages of the developed salt melt assisted approach.

\section{Introduction}

Photocatalytic water splitting into hydrogen and oxygen over a semiconductor photocatalyst using solar energy is a promising way of converting light energy into chemical energy of hydrogen $^{1}$ that is inspired by natural photosynthesis. Water oxidation is a crucial step of the overall process since it requires 4-electron and 4-proton transfers as well as $\mathrm{O}-\mathrm{O}$ bond formation, and is regarded as a critical bottleneck for creating technical photosynthetic devices, since this reaction completes the solar fuel cycle. ${ }^{2,3}$

Graphitic carbon nitride materials (CN-polymers) with the stoichiometry of $\mathrm{C}_{x} \mathrm{~N}_{y} \mathrm{H}_{z}(x=3, y \approx 4.2-5.2, z \approx 1-1.5)$ are processable ${ }^{4,5}$ organic polymeric semiconductors absorbing the

${ }^{a}$ Max-Planck Institute of Colloids and Interfaces, Department of Colloid Chemistry, Research Campus Golm, 14424 Potsdam, Germany. E-mail: dariya.dontsova@ mpikg.mpg.de

${ }^{b}$ State Key Laboratory of Photocatalysis on Energy and Environment, College of Chemistry, Fuzhou University, Fuzhou, 350002, People's Republic of China

${ }^{c}$ Institut für Chemie, Sekr. TC 2, Technische Universität Berlin, Englische Str. 20, 10587 Berlin, Germany

$\dagger$ Electronic supplementary information (ESI) available: Information about the eutectics used, O1s and $\mathrm{Cl} 2 \mathrm{p}$ XPS spectra of $\mathrm{KCl} / \mathrm{CoCl}_{2}$ derived products, EA and surface area data of products synthesized in different melts, $\mathrm{N}_{2}$ sorption isotherms, summary of activity in photocatalytic water oxidation, and the TEM image of $\mathrm{Co}_{3} \mathrm{O}_{4}$ nanoparticles. See DOI: 10.1039/c5ta06304c

\$ Current address: Institute of Nano Science and Technology (INST), Habitat Centre, Phase - 10, Sector - 64, Mohali, Punjab - 160062, India. high energy fraction of the visible light and having suitable band positions to perform water splitting ${ }^{6}$ which makes them promising candidates for full artificial photosynthesis. These polymers additionally offer the advantages of high thermal and chemical stability against oxidation. ${ }^{7}$ However, some carbon nitrides are known to undergo photocorrosion due to the limited mobility of the photogenerated holes and resulting selfoxidation while releasing nitrogen gas. The photocorrosion of the polymers can be minimized by the use of an efficient co-catalyst. ${ }^{6,8}$

Metal oxides as water oxidation catalysts are attractive because of their robustness, and oxides of noble metals, in particular $\operatorname{Ir}^{9-11}$ and $\mathrm{Ru},{ }^{12-14}$ are among the most efficient known oxygen evolving catalytic materials. However, their scarcity and the resulting high cost caused the need for exploring robust oxides of earth-abundant metals as efficient multi-electron catalysts for water oxidation, in particular first row transition metal oxides. Among these, cobalt oxides offer a suitable balance between reactivity, structural stability and resistance in the highly oxidative chemical environment of the oxygen evolution reaction. ${ }^{\mathbf{1 5}}$

Recently, cobalt oxide and cobalt(II) hydroxide containing carbon nitride composites were reported to be promising for water oxidation. ${ }^{\mathbf{8 1 6}}$ However, so far they were mostly prepared by using multistep procedures. A single-step synthesis procedure by mixing $\mathrm{CoCl}_{2}$ with dicyandiamide (DCDA) resulted in only a slight increase of the photocatalytic activity compared to the bulk CN-polymer. ${ }^{17}$ Thus, there is still a need for simple 
preparation methods of highly active composite photocatalysts comprising carbon nitride and catalytically active cobalt species.

Salt melt assisted synthesis of carbon nitrides can be used for the preparation of functional $\mathrm{CN}$-polymers by using one-step procedures. ${ }^{18-21}$ Bivalent metals remain in the final composites, partially as oxides resulting from the aqueous work-up of the reaction mixtures or the presence of oxygen during the synthesis. ${ }^{20,21}$ Making use of this observation, we here present a one-step procedure for the preparation of cobalt-containing carbon nitride-based photocatalysts by using the condensation reaction of dicyandiamide in $\mathrm{CoCl}_{2}$-containing eutectic salt mixtures.

\section{Experimental section}

\section{Materials}

Sodium chloride (99.5\%), potassium chloride (99.0\%), Rhodamine B (95.0\%) and trithiocyanuric acid (95.0) were purchased from Sigma-Aldrich. Zinc chloride (98.0\%), tin(II) chloride (98.0\%), cobalt(II) chloride (99.0\%), and silver nitrate (99.9\%) were purchased from Alfa Aesar, and dicyandiamide (DCDA, 98\%) from Merck. Lanthanum(III) oxide (99.9\%) was purchased from Fluka analytics. All the chemicals were used without further purification.

\section{Synthesis procedure}

Salts and dicyandiamide were ground together in a glovebox (mBraun Unilab, $\mathrm{O}_{2}<0.1 \mathrm{ppm}, \mathrm{H}_{2} \mathrm{O}<0.1 \mathrm{ppm}$ ) under an argon atmosphere according to eutectic compositions (Table S1 $\dagger$ ). Reaction mixtures $(\sim 5-10 \mathrm{~g})$ were transferred into porcelain crucibles and covered with lids. Crucibles were placed in the oven under a constant nitrogen flow $\left(15 \mathrm{~L} \mathrm{~min}^{-1}\right)$ and heated with a ramp of $10 \mathrm{~K} \mathrm{~min}^{-1}$ up to $550{ }^{\circ} \mathrm{C}$. The temperature was maintained for 6 hours, and then the samples were cooled down. The crude products were washed first with deionized water (50-100 mL) and then with $1 \mathrm{M} \mathrm{HCl}$ solution $(50-100 \mathrm{~mL})$ in order to remove the salts and the products of their hydrolysis. Each step was carried out for 24 hours. The final products were isolated by filtration, then thoroughly washed with deionized water $(500 \mathrm{~mL})$ and dried in a vacuum oven $(10 \mathrm{mbar})$ at $50{ }^{\circ} \mathrm{C}$ for $15 \mathrm{~h}$. Reference $\mathrm{CN}$ was prepared by heating DCDA with the ramp of $2.3{ }^{\circ} \mathrm{C} \min ^{-1}$ up to $550{ }^{\circ} \mathrm{C}$ and subsequently maintaining at this temperature for $4 \mathrm{~h}$ under a constant nitrogen flow $\left(15 \mathrm{~mL} \mathrm{~min}^{-1}\right.$ ) in a covered crucible. $\mathrm{CNS} / 3 \% \mathrm{Co}_{3} \mathrm{O}_{4}$ was prepared according to the described procedure. ${ }^{8}$

\section{Rhodamine B degradation experiments}

$5 \mathrm{mg}$ of the photocatalyst were dispersed in $5 \mathrm{~mL}$ of RhB solution in deionized water $\left(10 \mathrm{mg} \mathrm{\textrm {L } ^ { - 1 }}\right)$. The suspension was agitated in the dark for $0.5-2 \mathrm{~h}$ in order to reach a darkadsorption equilibrium and then illuminated with an LED module emitting white light $(\lambda>420 \mathrm{~nm}, 50 \mathrm{~W}$, Bridgelux $)$ from the fixed distance of $5 \mathrm{~cm}$. The RhB degradation was monitored as the decrease of the dye concentration over irradiation time. At specific time intervals $(t), 300 \mu \mathrm{L}$ aliquots of the reaction mixture were taken, diluted with $1.7 \mathrm{~mL}$ of deionized water, maintained for 30 minutes in the dark to enable catalyst precipitation, and then analyzed spectrophotometrically (T70 UV/VIS spectrophotometer of PG instruments Ltd). The reaction rate constants $k$ were calculated as the slopes of the linear fits of $\left[-\ln \left(A / A_{0}\right)\right]$ dependences on the irradiation time. Here, $A_{0}$ and $A$ are absorbance of the dye in the solution after dark equilibration and after irradiation time $t$ respectively, measured at $554 \mathrm{~nm}$, which are proportional to the dye concentrations in the solution $\left(C_{0}\right.$ and $\left.C\right)$.

\section{Photocatalytic oxygen evolution experiments}

Set up 1. Reactions were carried out in a Pyrex top-irradiation reaction vessel connected to a glass closed gas system. For each reaction, $50 \mathrm{mg}$ catalyst powder was well dispersed in an aqueous solution $(100 \mathrm{~mL})$ containing $\mathrm{AgNO}_{3}(0.01 \mathrm{M})$ as an electron acceptor and $\mathrm{La}_{2} \mathrm{O}_{3}(0.2 \mathrm{~g})$ as a $\mathrm{pH}$ buffering agent. The reaction solution was evacuated several times and then filled with argon, to remove air completely prior to irradiation with a $300 \mathrm{~W}$ Xenon lamp. The temperature of the reaction solution was maintained constant by using a flow of cooling water during the reaction. The evolved gases were analyzed by a gas chromatograph equipped with a thermal conductivity detector and a $5 \AA$ molecular sieve column, using argon as a carrier gas.

Set up 2. Reactions were carried out in a closed three-neck side irradiation reaction vessel. For each reaction, $50 \mathrm{mg}$ of catalyst were well dispersed in an aqueous solution $(20 \mathrm{~mL})$ containing $\mathrm{AgNO}_{3}(90 \mathrm{mg})$ used as an electron acceptor and $\mathrm{La}_{2} \mathrm{O}_{3}(0.1 \mathrm{~g})$ as a $\mathrm{pH}$ buffering agent. The reaction solution was purged with argon for several hours to completely remove oxygen prior to irradiation with a $300 \mathrm{~W}$ Xenon lamp. The temperature of the reaction solution was maintained constant by using a flow of cooling water during the reaction. Photocatalytic $\mathrm{O}_{2}$ evolution was monitored by using an oxygen probe (PreSens Precision Sensing GmbH, Fibox 3 fiber optic oxygen transmitter). Before illumination, the oxygen probe was calibrated with temperature compensation by using standard calibration solution 0 (oxygen-free water) and calibration solution 100 (air-saturated water). More details on the set-up are available in the literature. ${ }^{22}$

\section{Characterization}

Powder X-ray diffraction patterns were measured on a Bruker D8 Advance diffractometer equipped with a scintillation counter detector with $\mathrm{CuK} \alpha$ radiation $(\lambda=0.15418 \mathrm{~nm})$ by applying a $2 \theta$ step size of $0.05^{\circ}$ and a counting time of $3 \mathrm{~s}$ per step. FT-IR spectra were recorded on a Varian 1000 FT-IR spectrometer equipped with an attenuated total reflection unit applying a resolution of $4 \mathrm{~cm}^{-1}$. Nitrogen adsorption/desorption measurements were performed after degassing the samples at $150{ }^{\circ} \mathrm{C}$ for 20 hours using a Quantachrome Quadrasorb SI-MP porosimeter at 77.4 K. The specific surface areas were calculated by applying the Brunauer-Emmett-Teller (BET) model to adsorption isotherms for $0.05<p / p_{0}<0.3$ using the QuadraWin 5.05 software package. Elemental analysis (EA) was accomplished as a combustion analysis using a Vario Micro device. 
Scanning electron microscopy (SEM) images were obtained by using a LEO 1550-Gemini microscope. Optical absorbance spectra of powders were measured on a Shimadzu UV 2600 equipped with an integrating sphere. The absorption spectra of RhB solutions were recorded on a T70 UV/VIS spectrophotometer (PG instruments Ltd). The emission spectra were recorded using LS-50B, a Perkin-Elmer instrument. The excitation wavelength was $350 \mathrm{~nm}$. Energy-dispersive X-ray spectroscopy (EDS) investigations were conducted on a JEOL JSM-7500F microscope using a Link ISIS-300 system (Oxford Microanalysis Group) equipped with a $\mathrm{Si}(\mathrm{Li})$ detector with an energy resolution of $133 \mathrm{eV}$, at 5-12 keV. X-ray photoelectron spectroscopy (XPS) was performed on a Multilab 2000 (Thermo) spectrometer equipped with the $\mathrm{Al} \mathrm{K} \alpha$ anode $(h \nu=1486.6 \mathrm{eV})$. All spectra were referenced to the $\mathrm{C}$ 1s peak of adventitious carbon at $285.0 \mathrm{eV}$. For quantification purposes, survey spectra at pass energy of $50 \mathrm{eV}$ and high-resolution spectra at pass energy of $20 \mathrm{eV}$ were recorded and analyzed by using XPS Peak 4.1 software (by Raymond Kwok). The spectra were decomposed assuming line shapes as the sum of Gaussian (80\%) and Lorentzian (20\%) functions. Raw areas determined after subtraction of a Shirley background ${ }^{23}$ were corrected according to the following sensitivity factors: ${ }^{24} \mathrm{C} 1 \mathrm{~s}-0.25 ; \mathrm{N} 1 \mathrm{~s}-0.42 ; \mathrm{O} 1 \mathrm{~s}-0.66 ; \mathrm{Cl} 2 \mathrm{p}-0.73$, $\mathrm{Co} 2 \mathrm{p}-3.8$. Inductively coupled plasma atomic emission spectroscopy (ICP-AES) analysis was performed on a Perkin-Elmer ICP OES 8000.

\section{Results and discussion}

First, the concentration of the carbon nitride precursor, dicyandiamide, was maintained constant by using 1:5 DCDA to salts weight ratio, while the nature of the second component of eutectics was varied (see Table $\mathbf{S} 1 \dagger$ ). The composition of the resulting products is shown in Table $\mathrm{S} 2, \dagger$ as determined by elemental analysis, energy-dispersive X-ray spectroscopy (EDS) and inductively coupled plasma (ICP) studies. The obtained solids are mainly composed of carbon and nitrogen and are characterized by the $\mathrm{C} / \mathrm{N}$ weight ratios of 0.58 to 0.63 . These numbers are higher than the $\mathrm{C} / \mathrm{N}$ weight ratio in the reference material prepared by the bulk condensation of DCDA (0.58), referred to as ref.-CN, but still slightly lower than the theoretical value for the perfect $\mathrm{C}_{3} \mathrm{~N}_{4}$ (0.64). The $\mathrm{CoCl}_{2}$-derived solids contain significant amounts of oxygen that comes with the increased hydrogen content if compared to the ref.-CN; both are due to the presence of surface-adsorbed water and surface hydroxyl-groups as corroborated by the X-ray photoelectron spectroscopy (XPS) investigations.

The XPS studies of a sample product obtained from the $\mathrm{KCl} / \mathrm{CoCl}_{2}$ salt melt showed that the carbon nitride part of the composite is based on poly(triazine imide) (PTI). Namely, the C1s signal (Fig. 1a) contains four contributions: the major one at $288.5 \mathrm{eV}$ assigned to $\mathrm{CN}_{3}$ bonds, ${ }^{25}$ and the minor ones at $286.9 \mathrm{eV}$ corresponding to the surface $\mathrm{C}-\mathrm{OH}$ groups and at $283.1 \mathrm{eV}$ due to some carbide impurities, together with the peak of adventitious carbon at $285.0 \mathrm{eV}$. The N1s signal (Fig. 1b) can be deconvoluted into three peaks at $400.3 \mathrm{eV}$ due to $\mathrm{NH}_{x}$ groups $(x=1,2)$, at $398.8 \mathrm{eV}$ assigned to $\mathrm{C}=\mathrm{N}-\mathrm{C}$ bonds and minor a)

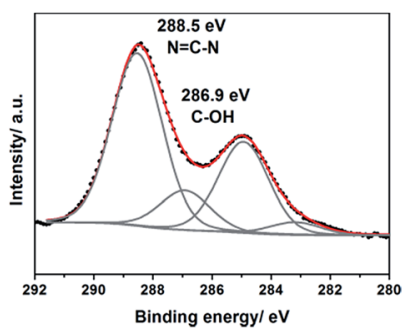

c)

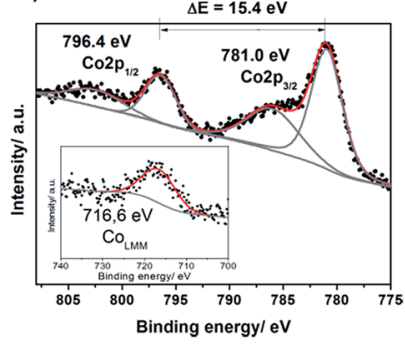

b)

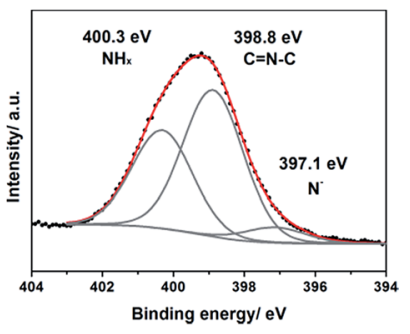

d)

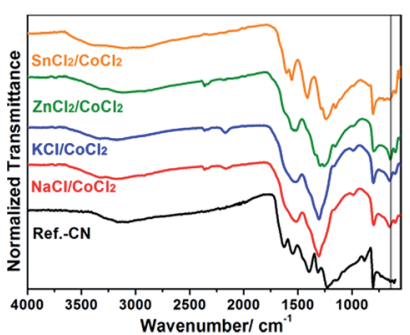

Fig. 1 C1s (a), N1s (b) XPS spectra, Co2p spectrum (c) and COLMM Auger line (inset in $\mathrm{c}$ ) of the product prepared in $\mathrm{KCl} / \mathrm{CoCl}_{2} ; \mathrm{FTIR}$ spectra of the $\mathrm{CoCl}_{2}$-derived products and the reference $\mathrm{CN}$-polymer (d). The vertical line in (d) indicates the $650 \mathrm{~cm}^{-1}$ position.

contribution of the deprotonated nitrogen atoms at $397.1 \mathrm{eV}$. The absence of the fourth N1s peak of tertiary nitrogen and the high content of $\mathrm{NH}_{x}$ groups expressed as a high peak area suggest that the obtained $\mathrm{CN}$-polymer is based on $s$-triazine but not tri-s-triazine repeating units. This conclusion is further supported by the previous reports on the simulated ${ }^{26}$ and measured XPS spectra of poly(triazine imides). ${ }^{20}$

Inductively coupled plasma (ICP) and energy-dispersive $\mathrm{X}$-ray spectroscopy (EDS) investigations showed that the cobalt content in the composites is 3-6 wt\% (Table S2†). Cobalt is present in both $\mathrm{Co}$ (II) and $\mathrm{Co}(\mathrm{III})$ oxidation states as follows from the results of the XPS studies (Fig. 1c). The Co2p spectrum (Fig. 1c) consists of the Co2 $\mathrm{p}_{3 / 2}$ contribution at $781.0 \mathrm{eV}$, its corresponding satellite peak at $786.0 \mathrm{eV}$ and the Co2 $\mathrm{p}_{1 / 2}$ contribution at $796.4 \mathrm{eV}$ along with the satellite peak at $802.4 \mathrm{eV}$. The Co2 $\mathrm{p}_{1 / 2}-\mathrm{Co} 2 \mathrm{p}_{3 / 2}$ spin-orbit splitting makes up $15.4 \mathrm{eV}$ which is in between $15 \mathrm{eV}$ observed for the pure $\mathrm{Co}(\mathrm{III})$ state and $16 \mathrm{eV}$ typical for the pure $\mathrm{Co}(\mathrm{II})$ state, ${ }^{27}$ and points to the coexistence of $\mathrm{Co}$ (II) and $\mathrm{Co}(\mathrm{III})$ species in the products.

Further evidence of the presence of both valence states of cobalt is provided by the position of the $\mathrm{Co}_{\text {LMM }}$ Auger line (Fig. 1c, inset). The peak is located at $716.6 \mathrm{eV}$ that corresponds to a kinetic energy of $770 \mathrm{eV}$. The modified Auger parameter, $\alpha$, can be calculated according to the following equation: ${ }^{28}$

$$
\alpha=1486.6 \mathrm{eV}+\mathrm{KE}\left(\mathrm{Co}_{\mathrm{LMM}}\right)-\mathrm{KE}\left(\mathrm{Co} 2 \mathrm{p}_{3 / 2}\right)=1551.0 \mathrm{eV}
$$

where KE is kinetic energy.

This value of $\alpha$ is in between the reported values for $\mathrm{CoO}$ $(\alpha=1549.8 \mathrm{eV})$ and $\mathrm{Co}_{3} \mathrm{O}_{4}(\alpha=1552.9 \mathrm{eV})$ thus indicating the coexistence of $\mathrm{Co}(\mathrm{II})$ and $\mathrm{Co}(\mathrm{III})$. 
The charge of cobalt is balanced by oxygen and chlorine suggesting that Co is present as cobalt (II, III) oxide and, partially, as entrapped chloride containing complexes, likely, of cobalt(III), since they are known to be kinetically inert and could easily withstand the aqueous workup of the crude products. The O1s signal (Fig. S1a†) consists of three contributions with the binding energies at $533.1 \mathrm{eV}$ due to the surface adsorbed water, at $531.5 \mathrm{eV}$ assigned to the hydroxyl groups and the peak of cobalt (II, III) oxides at $529.9 \mathrm{eV}^{29,30}$ The Cl2p spectrum shown in Fig. S1b $\uparrow$ reveals a single contribution at $197.6 \mathrm{eV}$ assigned to Co-Cl bonds. ${ }^{31}$

SEM-EDS investigations revealed that the distribution of Co in the composites is fairly homogeneous, as illustrated by the corresponding elemental maps of $\mathrm{KCl} / \mathrm{CoCl}_{2}$ and $\mathrm{SnCl}_{2} / \mathrm{CoCl}_{2}-$ derived products in Fig. S2. $\dagger$

The results of the FTIR studies shown in Fig. 1d further corroborate the XPS findings. Poly(triazine imides) are formed in NaCl-, $\mathrm{KCl}-$ and $\mathrm{ZnCl}_{2} / \mathrm{CoCl}_{2}$ salt melts as can be recognized by the presence of the distinct characteristic peak of the $s$-triazine ring at $650 \mathrm{~cm}^{-1} .{ }^{32}$ This peak is absent in the cases of the bulk carbon nitride and $\mathrm{SnCl}_{2} / \mathrm{CoCl}_{2}$ products suggesting that their structure is based on tri-s-triazine units. PXRD studies further corroborate this assumption (see below). The broad absorption band at $2400-3650 \mathrm{~cm}^{-1}$ suggests the presence of the surface hydroxyl groups, surface adsorbed water and terminal amino-groups in the obtained materials, while the main absorption band at $1100-1650 \mathrm{~cm}^{-1}$ is due to $\mathrm{CN}$ stretching and $\mathrm{NH}$ bending in aromatic heterocycles ${ }^{33}$ and is typical for carbon nitride polymers. ${ }^{18,34,35}$

Therefore, we conclude that the nature of the second component of the eutectic determines the chemical structure of the carbon nitride part of the composite. Here, alkali metal salts and $\mathrm{ZnCl}_{2}$ give rise to poly(triazine imides), while $\mathrm{SnCl}_{2}$ leads to the formation of melon-based products. This can be explained by the strength and reversibility of the binding of mono- ( $\mathrm{Na}, \mathrm{K})$ and divalent $(\mathrm{Zn}, \mathrm{Sn})$ metal ions to the condensation intermediates such as melamine and melam during synthesis. Strong binding, typical for alkali metal ions and for $\mathrm{ZnCl}_{2}$ known to be a strong Lewis acid, stabilizes these $s$-triazine-based intermediates and prohibits their transformation to tri-s-triazine species, that leads to the $s$-triazine-based polymer, poly(triazine imide). Conversely, weak and reversible binding of $\mathrm{SnCl}_{2}$, a milder Lewis acid compared to $\mathrm{ZnCl}_{2}$, enables the conversion of the $s$-triazine ring to the tri-s-triazine one, but stabilizes 1D melon chains preventing their further condensation to form graphitic carbon nitride. ${ }^{21}$

The products are mainly short-range ordered as suggested by the appearance of the corresponding PXRD patterns (Fig. 2a) due to both poor solubilizing properties of $\mathrm{CoCl}_{2}$ being a weak Lewis acid and relatively high melting points of some eutectics (Table S1 $\dagger$ ). This results in an early phase demixing of the melt and polymerization intermediates preventing crystallization of the polymers from the melt. The two main peaks characterizing the interlayer stacking at $\sim 27^{\circ} 2 \theta$ and the in-layer repeating motif at $\sim 13^{\circ} 2 \theta$ are broadened in the obtained solids compared to the reference bulk CN-polymer. In the pattern of the $\mathrm{SnCl}_{2} / \mathrm{CoCl}_{2}$-derived product, the characteristic peak of the a)

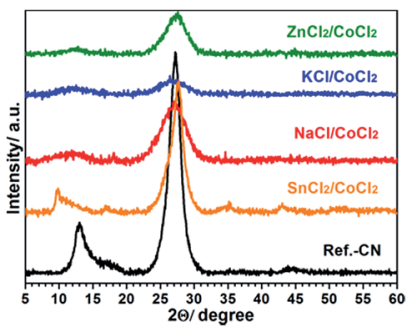

b)

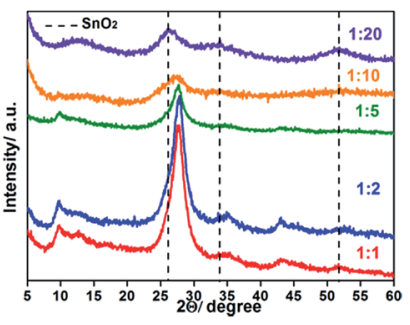

Fig. 2 PXRD patterns of the products prepared in $\mathrm{NaCl} / \mathrm{CoCl}_{2}$, $\mathrm{KCl} / \mathrm{CoCl}_{2}, \mathrm{ZnCl}_{2} / \mathrm{CoCl}_{2}$ and $\mathrm{SnCl}_{2} / \mathrm{CoCl}_{2}$ eutectics at $1: 5$ precursor to salt weight ratio (a), in the $\mathrm{SnCl}_{2} / \mathrm{CoCl}_{2}$ eutectic using different precursor to salt weight ratios (b).

in-layer order is shifted to lower angles $\left(2 \theta=9.8^{\circ}\right)$ suggesting the formation of a chain-like polymer, presumably melon, as previously reported for the $\mathrm{SnCl}_{2}$-derived products. ${ }^{21}$

However, the crystallinity of the resulting composites can be tuned by adjusting the precursor concentration in the melt. Fig. 2b shows PXRD patterns of the products prepared in the $\mathrm{SnCl}_{2} / \mathrm{CoCl}_{2}$ eutectics using different weight ratios of dicyandiamide to the salts, namely $1: 1,1: 2,1: 5,1: 10$ and $1: 20$. High precursor concentrations $(1: 1$ and $1: 2)$ favor the formation of polymers featuring a high structural order, while the decrease of DCDA concentration leads to the less ordered solids. Finally, at $1: 20$ ratio, mainly $\mathrm{SnO}_{2} \mathrm{NP}$ reflections are observed in the corresponding PXRD pattern. The decrease of the crystallinity in the final products upon decrease of the precursor concentration is due to the termination of the crystal growth by the deposition of some metal species from the melt onto the crystal facets, as illustrated by the increase of the metal content in the isolated products (Table S3†). On the other hand, no crystalline cobalt-containing species could be detected under any synthesis conditions used.

The suggested preparation method delivers non-porous composites with the surface areas between 6 and $51 \mathrm{~m}^{2} \mathrm{~g}^{-1}$ (Fig. S3 $\uparrow$ ). These values are much higher than provided by bulk synthesis $\left(1 \mathrm{~m}^{2} \mathrm{~g}^{-1}\right)$. The selected SEM images of products are shown in Fig. 3. Two different morphologies are typical for the $\mathrm{CoCl}_{2}$-derived products: spherical particles are formed in alkali metal chloride and $\mathrm{ZnCl}_{2}$-containing eutectics, while plate-like particles are obtained from the $\mathrm{SnCl}_{2} / \mathrm{CoCl}_{2}$ salt melts. The latter carbon nitride particle morphology along with its a)

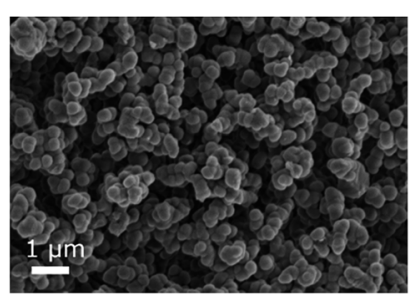

b)

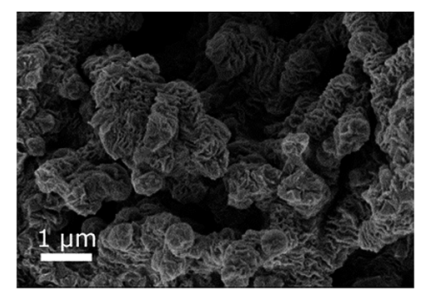

Fig. 3 SEM images of the composites prepared in $\mathrm{KCl} / \mathrm{CoCl}_{2}$ (a) and $\mathrm{SnCl}_{2} / \mathrm{CoCl}_{2}$ (b) salt melts. 
chemical structure are typical for CN-polymers prepared in $\mathrm{SnCl}_{2}$-based eutectics, in agreement with the previous report. ${ }^{21}$

In Fig. $4 \mathrm{a}$, the optical absorption properties of $\mathrm{CoCl}_{2}$-derived materials are compared with those of the composite photocatalyst consisting of tri-thiocyanuric acid derived carbon nitride and $5 \mathrm{~nm} \mathrm{Co}_{3} \mathrm{O}_{4}$ NPs that was prepared in 3 steps according to the reported procedure ${ }^{8}$ (Fig. S4 $\dagger$ ) and used as a reference catalyst in the photocatalytic water oxidation reaction (see below). The products of the salt melt synthesis are characterized by a significantly improved absorption in the visible light range than the reference material. Unlike CNS/3wt\%$\mathrm{Co}_{3} \mathrm{O}_{4}$ composites exhibiting a distinct absorption at $\sim 700 \mathrm{~nm}$ due to the $\mathrm{O}^{2-} \rightarrow \mathrm{Co}^{3+}$ electron transition, ${ }^{8,36-38}$ the smooth appearance of the absorption spectra of $\mathrm{CoCl}_{2}$-derived solids suggests the formation of the dyadic system with a shared electron density, where cobalt species are integrated into the carbon nitride electronic structure enabling a continuum of new electron transitions upon excitation with visible light. The phenomenon was previously reported for carbon@ $\mathrm{TiO}_{2}$ composites $^{39}$ and $\mathrm{CN}$-polymer composites prepared in $\mathrm{ZnCl}_{2}$-containing salt melts. ${ }^{20}$

All $\mathrm{CoCl}_{2}$-derived solids are characterized by almost negligible PL signals (Fig. 4b) that can only partially be explained by the decreased X-ray structural order, but mainly suggest the improved charge separation of the photo-excited charge carriers which is responsible for the high photocatalytic performance of the composites as illustrated below.

\section{Photocatalytic studies}

We found that $\mathrm{CoCl}_{2}$-derived composites are active catalysts for the photocatalytic water oxidation reaction. The composites were tested in two different set-ups, whose detailed description is given in the experimental part, using $\mathrm{AgNO}_{3}$ as a sacrificial electron scavenger and $\mathrm{La}_{2} \mathrm{O}_{3}$ as a $\mathrm{pH}$ buffering agent upon irradiation with a $300 \mathrm{~W}$ Xenon lamp $(\lambda>300 \mathrm{~nm})$. The amounts of the produced oxygen were quantified either by gas chromatography (set up 1) or using an optical oxygen probe (set up 2). Additionally, gas chromatography was used in order to determine the $\mathrm{O}_{2} / \mathrm{N}_{2}$ selectivity characterizing the stability of carbon nitride polymers during the photocatalytic reaction.

The $\mathrm{O}_{2}$ evolution rates provided by using the $\mathrm{CoCl}_{2}$-derived products are comparable with those achieved by using the a)

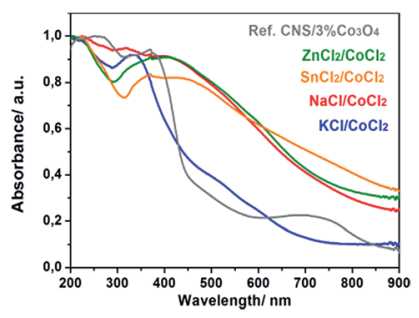

b)

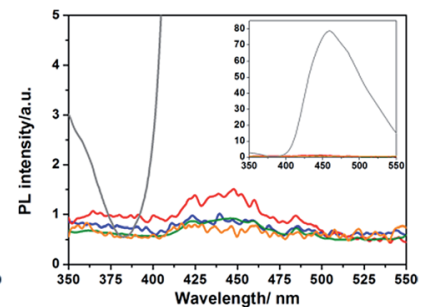

Fig. 4 Optical absorption (a) and emission (b) spectra of the products prepared in $\mathrm{NaCl} / \mathrm{CoCl}_{2}, \mathrm{KCl} / \mathrm{CoCl}_{2}, \mathrm{ZnCl}_{2} / \mathrm{CoCl}_{2}$ and $\mathrm{SnCl}_{2} / \mathrm{CoCl}_{2}$ eutectics and the reference $\mathrm{CNS} / 3 \mathrm{wt} \% \mathrm{CO}_{3} \mathrm{O}_{4}$ composite prepared according to the reported procedure. ${ }^{8}$ a)

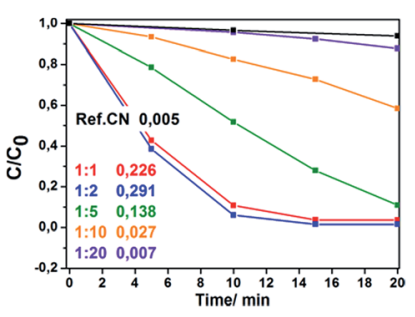

b)

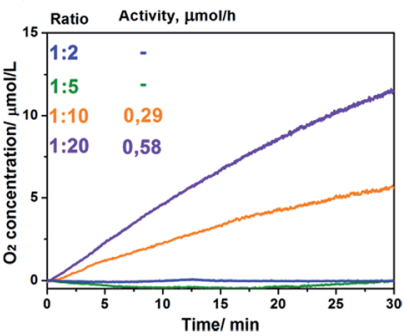

Fig. 5 The decrease of the relative Rhodamine B concentration and calculated rate constants in $\min ^{-1}$ (a) and increase of the $\mathrm{O}_{2}$ concentration (b) as a function of the irradiation time using $\mathrm{SnCl}_{2} / \mathrm{CoCl}_{2}$-derived photocatalysts prepared using different precursor to salt ratios. Reaction conditions are given in the Experimental section.

benchmark composite, $\mathrm{CNS} / 3 \mathrm{wt} \%-\mathrm{Co}_{3} \mathrm{O}_{4}$ (Table $\mathrm{S} 4 \dagger$ ). Moreover, the products of the salt melt synthesis show high $\mathrm{O}_{2} / \mathrm{N}_{2}$ selectivity, in most of cases even higher than that of the reference material, suggesting that carbon nitrides are stable during the reaction. Thus, we conclude that cobalt present as cobalt (II, III) oxide clusters and even amorphous chloride-containing cobal$\mathrm{t}(\mathrm{III})$ complexes, indeed, successfully serves as an efficient co-catalyst for water oxidation, which is in agreement with the recent reports..$^{15,40,41}$

Since the crystallinity of a photocatalyst is known to play an important role in its photocatalytic performance, we investigated the influence of the structural order of the CN-polymer component of the $\mathrm{SnCl}_{2} / \mathrm{CoCl}_{2}$-derived products on the reaction rates in Rhodamine B degradation and water oxidation (Fig. 5). The products with a high structural order (prepared at $1: 1$ and $1: 2$ precursor to salt ratios) are found to be highly active photocatalysts for dye degradation upon irradiation with white light $(\lambda>420 \mathrm{~nm})$, providing the rate constants $(0.226$ and $0.291 \mathrm{~min}^{-1}$, respectively) that are $45-58$ times higher compared to the ground bulk CN-polymer $\left(k=0.005 \mathrm{~min}^{-1}\right)$. Upon decrease of the structural order, the reaction constant decreases gradually to $k=0.007 \mathrm{~min}^{-1}$ (Fig. 5a). Such photocatalytic behavior is explained by the lower energy losses via recombination or phonon release and the resulting higher reaction rates in the case of defect-free or more crystalline products.

Conversely, the products prepared using low precursor concentrations in the melt $(1: 20,1: 10$ ratios) show superior performance for the water oxidation reaction compared to those prepared at low concentrations (Fig. 5b). This is explained by higher amounts of cobalt species deposited on the surface of the former products (for comparison of cobalt content, see Table S3 $\dagger$ ), and proves that these serve as active sites for $\mathrm{O}_{2}$ evolution.

\section{Conclusion}

The thermal condensation of dicyandiamide in $\mathrm{CoCl}_{2}$-containing eutectics yields cobalt-containing carbon nitride-based photocatalysts. Cobalt is incorporated in the final products as cobalt (II, III) oxide clusters and amorphous chloride-containing 
cobalt(III) complexes that successfully play the role of co-catalysts in the photocatalytic water oxidation reaction. The composites obtained are characterized by the improved optical absorption in the visible light range due to the formation of the dyadic system between carbon nitride polymer and cobalt species, and almost negligible photoluminescence due to the improved charge separation. The high crystallinity of the carbon nitride phase provides high Rhodamine B degradation rates, while oxygen evolution rates are mainly dependent on the cobalt co-catalyst loading. Both parameters can be successfully tuned by varying the synthesis conditions.

\section{References}

1 K. Maeda, J. Photochem. Photobiol., C, 2011, 12, 237.

2 N. S. Lewis and D. G. Nocera, Proc. Natl. Acad. Sci. U. S. A., 2006, 103, 15729.

3 M. W. Kanan and D. G. Nocera, Science, 2008, 321, 1072.

4 Z. Zhou, J. Wang, J. Yu, Y. Shen, Y. Li, A. Liu, S. Liu and Y. Zhang, J. Am. Chem. Soc., 2015, 137, 2179.

5 J. Wang, C. Zhang, Y. Shen, Z. Zhou, J. Yu, Y. Li, W. Wei, S. Liu and Y. Zhang, J. Mater. Chem. A, 2015, 3, 5126.

6 X. Wang, K. Maeda, A. Thomas, K. Takanabe, G. Xin, J. M. Carlsson, K. Domen and M. Antonietti, Nat. Mater., 2009, 8, 76.

7 J. R. Holst and E. G. Gillan, J. Am. Chem. Soc., 2008, 130, 7373. 8 J. Zhang, M. Grzelczak, Y. Hou, K. Maeda, K. Domen, X. Fu, M. Antonietti and X. Wang, Chem. Sci., 2012, 3, 443.

9 W. J. Youngblood, S.-H. A. Lee, Y. Kobayashi, E. A. Hernandez-Pagan, P. G. Hoertz, T. A. Moore, A. L. Moore, D. Gust and T. E. Mallouk, J. Am. Chem. Soc., 2009, 131, 926.

10 T. Nakagawa, N. S. Bjorge and R. W. Murray, J. Am. Chem. Soc., 2009, 131, 15578.

11 P. G. Hoertz, Y. I. Kim, W. J. Youngblood and T. E. Mallouk, J. Phys. Chem. B, 2007, 111, 6845.

12 J. Sato, N. Saito, Y. Yamada, K. Maeda, T. Takata, J. N. Kondo, M. Hara, H. Kobayashi, K. Domen and Y. Inoue, J. Am. Chem. Soc., 2005, 127, 4150.

13 P. Baltzer, R. S. Davidson, A. C. Tseung, M. Grätzel and J. Kiwi, J. Am. Chem. Soc., 1984, 106, 1504.

14 Y. Lee, J. Suntivich, K. J. May, E. E. Perry and Y. Shao-Horn, J. Phys. Chem. Lett., 2012, 3, 399.

15 F. Jiao and H. Frei, Energy Environ. Sci., 2010, 3, 1018.

16 G. Zhang, S. Zang and X. Wang, ACS Catal., 2015, 5, 941.

17 G. Zhang, C. Huang and X. Wang, Small, 2015, 11, 1215.

18 E. Wirnhier, M. Döblinger, D. Gunzelmann, J. Senker, B. V. Lotsch and W. Schnick, Chem.-Eur. J., 2011, 17, 3213.

19 S. Y. Chong, J. T. A. Jones, Y. Z. Khimyak, A. I. Cooper, A. Thomas, M. Antonietti and M. J. Bojdys, J. Mater. Chem. A, 2013, 1, 1102.

20 C. Fettkenhauer, J. Weber, M. Antonietti and D. Dontsova, RSC Adv., 2014, 4, 40803.
21 C. Fettkenhauer, G. Clavel, K. Kailasam, M. Antonietti and D. Dontsova, Green Chem., 2015, 17, 3350.

22 X. Yang, H. Tang, J. Xu, M. Antonietti and M. Shalom, ChemSusChem, 2015, 8, 1350.

23 D. A. Shirley, Phys. Rev. B: Solid State, 1972, 5, 4709.

24 C. D. Wagner, L. E. Davis, M. V. Zeller, J. A. Taylor, R. H. Raymond and L. H. Gale, Surf. Interface Anal., 1981, $3,211$.

25 A. Thomas, A. Fischer, F. Goettmann, M. Antonietti, J.-O. Muller, R. Schlogl and J. M. Carlsson, J. Mater. Chem., 2008, 18, 4893.

26 E. J. McDermott, E. Wirnhier, W. Schnick, K. S. Virdi, C. Scheu, Y. Kauffmann, W. D. Kaplan, E. Z. Kurmaev and A. Moewes, J. Phys. Chem. C, 2013, 117, 8806.

27 T. J. Chuang, C. R. Brundle and D. W. Rice, Surf. Sci., 1976, 59, 413.

28 R. Moreno-Tost, J. Santamaria-Gonzalez, P. Maireles-Torres, E. Rodriguez-Castellon and A. Jimenez-Lopez, Appl. Catal., B, 2002, 38, 51.

29 B. W. Lee, J. A. Taylor and J. W. Rabalais, Solid State Commun., 1980, 33, 1205.

30 C. R. Brundle, T. J. Chuang and D. W. Rice, Surf. Sci., 1976, 60, 286.

31 Insight into the exchange coupling between magnetic molecules and the supporting surface: spectromicroscopy correlation including X-ray magnetic circular dichroism, D. J. Chylarecka, Universität Basel, 2011.

32 D. Lin-Vien, N. B. Colthup, W. G. Fateley and J. G. Grasselli, The Handbook of Infrared and Raman Characteristic Frequencies of Organic Molecules, Academic Press limited, 1991.

$33 \mathrm{~J}$. Coates, Interpretation of Infrared Spectra, a Practical Approach, John Wiley \& Sons Ltd, Chichester, 2000.

34 A. B. Jorge, D. J. Martin, M. T. S. Dhanoa, A. S. Rahman, N. Makwana, J. Tang, A. Sella, F. Corà, S. Firth, J. A. Darr and P. F. McMillan, J. Phys. Chem. C, 2013, 117, 7178.

35 M. J. Bojdys, J.-O. Müller, M. Antonietti and A. Thomas, Chem.-Eur. J., 2008, 14, 8177.

36 J. D. Cook and M. P. van der Meer, Thin Solid Films, 1986, 144, 165.

37 I. D. Belova, Y. E. Roginskaya, R. R. Shifrina, S. G. Gagarin, Y. V. Plekhanov and Y. N. Venevtsev, Solid State Commun., 1983, 47, 577.

38 M. Ando, T. Kobayashi and M. Haruta, Sens. Actuators, B, 1996, 32, 157.

39 L. Zhao, X. Chen, X. Wang, Y. Zhang, W. Wei, Y. Sun, M. Antonietti and M.-M. Titirici, Adv. Mater., 2010, 22, 3317.

40 K. Klingan, F. Ringleb, I. Zaharieva, J. Heidkamp, P. Chernev, D. Gonzalez-Flores, M. Risch, A. Fischer and H. Dau, ChemSusChem, 2014, 7, 1301.

41 K. Kwapien, S. Piccinin and S. Fabris, J. Phys. Chem. Lett., 2013, 4, 4223. 